\title{
Triterpenoids and coumarins from the leaves of Sterculia foetida Linn.
}

\author{
Pham Nguyen Kim Tuyen ${ }^{1}$, Nguyen Thi Quynh Trang ${ }^{1}$, Huynh Cong Doan ${ }^{2}$, Pham Dinh Thuong ${ }^{3}$, \\ Nguyen Trung Duan ${ }^{4}$, Tran Doan Duy Cuong ${ }^{5}$, Huynh Bui Linh $\mathrm{Chi}^{6}{ }^{6}$, Nguyen Thi Anh Tuyet ${ }^{7}$, \\ Nguyen Kim Phi Phung ${ }^{8}$, Nguyen Thi Hoai Thu ${ }^{9, *}$
}

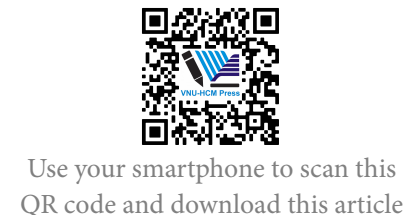

${ }^{1}$ Faculty of Environmental Science, Sai Gon University, Ho Chi Minh City

${ }^{2} \mathrm{Ca}$ Mau Medical College, Ca Mau Province

${ }^{3}$ Duc Linh High School, Binh Thuan Province

${ }^{4}$ Chau Thanh High School, Ba Ria- Vung Tau Province

${ }^{5}$ Trang Bang High School, Tay Ninh Province

${ }^{6}$ Department of Nature, Dong Nai University, Dong Nai Province

${ }^{7}$ Department of Chemistry, Ho Chi Minh City University of Education, Ho Chi Minh City

${ }^{8}$ Faculty of Chemistry, University of Science, Viet Nam National University Ho Chi Minh City, Ho Chi Minh City

${ }^{9}$ Faculty of Basic Sciences, University of Medicine and Pharmacy at Ho Chi Minh City, Ho Chi Minh City

Correspondence

Nguyen Thi Hoai Thu, Faculty of Basic Sciences, University of Medicine and Pharmacy at Ho Chi Minh City, Ho Chi Minh City

Email: nguyenthihoaithu@ump.edu.vn; hoaithudhyd@gmail.com

History

- Received: 2020-08-27

- Accepted: 2020-10-17

- Published: 2020-11-08

DOI : 10.32508/stdj.v23i4.2449

\section{Check for updates}

\section{Copyright}

(c) VNU-HCM Press. This is an openaccess article distributed under the terms of the Creative Commons Attribution 4.0 International license.

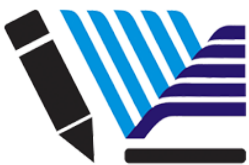

VNU-HCM Press

\begin{abstract}
Introduction: Sterculia foetida Linn. is widely distributed in tropical countries. As the continuous study on the hexane and ethyl acetate extracts of Sterculia foetida leaves, the isolation and structural determination of four triterpenoids and two coumarins were addressed. Method: The crude extract was prepared from dried power of Sterculia foetida leaves by maceration method in ethanol. This extract was then separated by liquid-liquid partition with n-hexane, chloroform, and ethyl acetate, respectively, to obtain the corresponding extracts. The hexane and ethyl acetate extracts were applied to multiple silica gel column chromatography to yield six compounds. Their chemical structures were determined by the NMR data analysis as well as the comparison their spectroscopic data and physical properties with those of reported literature. Results: Four triterpenoid compounds, including betulinic acid (1), conyzasaponin G (2), taraxerol (3), and taraxer-14-ene$1 \boldsymbol{\alpha}, 3 \beta$-diol (4), and two coumarins fraxetin (5), and aesculin (6) were identified. Conclusion: To the best of our knowledge, they have not been reported in the leaves of Sterculia foetida before, and compound $\mathbf{2}$ was known to present in Sterculia genus for the first time.

Key words: Sterculia foetida Linn., triterpenoid, coumarin
\end{abstract}

\section{INTRODUCTION}

Sterculia foetida Linn. belonging to Sterculiaceae is grown in tropical areas ${ }^{1}$. Leaves of Sterculia foetida Linn. are used in traditional medicine as an aperient, diuretic, and insect repellent ${ }^{2,3}$. There were some previous studies on chemical constituents of different parts of this species, which reported the presence of steroids, flavonoids, phenolic, coumarins, phenylpropanoids, and cerebrosides ${ }^{2-5}$. Previously, we reported the isolation of the organic compounds from leaves of this species collected in Binh Thuan province, including some triterpenoids, quercetin derivatives, and phenolic compound ${ }^{6,7}$. Herein, the continuous chemical study on the hexane and ethyl acetate extracts of Sterculia foetida leaves was discussed.

\section{MATERIALS AND METHODS}

\section{General experimental procedures}

The NMR spectra were obtained on a BRUKER AC 500 spectrometer $\left(500 \mathrm{MHz}\right.$ for ${ }^{1} \mathrm{H}-\mathrm{NMR}$ and 125 $\mathrm{MHz}$ for $\left.{ }^{13} \mathrm{C}-\mathrm{NMR}\right)$. The SCIEX X500 QTOF and X500 QTOF machines were used to record the high resolution-mass spectra and the ESI/APCI mass spectra, respectively. Column chromatography was ap- plied to the silica gel normal-phase (Kieselgel 60, 230400 mesh, Merck). The thin-layer chromatography technique was done by using silica gel plates (Kieselgel $60 \mathrm{~F}_{254}, 0.25 \mathrm{~mm}$, Merck).

\section{Plant material}

The S. foetida leaves were collected in Binh Thuan Province in October 2017. The scientific name of this plant was determined by botanist Dr. Dang Van Son, Institute of Tropical Biology. A voucher specimen, coded No.SFC/TUYEN-1017A, was deposited at the laboratory of Faculty of Environmental Science, Saigon University.

\section{Extraction and isolation}

The extraction procedure to obtain $1830 \mathrm{~g}$ crude extract by maceration method for three times $(3 \mathrm{x} 40$ $\mathrm{L}$ ethanol) at room temperature and partitioned extracts including $450 \mathrm{~g}$ of hexane, $650 \mathrm{~g}$ of chloroform, $30 \mathrm{~g}$ of ethyl acetate extracts, and the remaining layer by liquid-liquid partition method was shown more detail in ${ }^{7}$.

From the hexane extract ( $450.5 \mathrm{~g}$ ), seven fractions were separated by silica gel column chromatography and eluted with hexane-ethyl acetate (1:0, 3:1, 1:1, 
1:3, 0:1, v/v, respectively). Fraction SFH.III (60.0 g) was subjected to silica gel column chromatography, eluted with hexane-ethyl acetate (20:1, 9:1, 4:1, 3:2, 1:1) to yield four subfractions. Subfraction SFH.III.2 (18.0 g) was rechromatographed on silica gel column eluting with hexane-ethyl acetate $(20: 1,10: 1,5: 1)$ and repeated this process three times to obtain 3 (15.0 $\mathrm{mg}$ ). The same procedure was applied to subfraction SFH.III.4 (15.2 g) to yield 4 (25.3 mg). Fraction SFH.IV (75.0 g) was applied to a silica gel column and eluted with hexane: ethyl acetate $(10: 1,5: 1,3: 1,1: 1)$ to afford four subfractions. Subfraction SFH.IV.3 (20.8 g) was applied to silica gel column and eluted with a solvent system of $n$-hexane-ethyl acetate (3:1) and repeated this process three times on subfractions containing the main compound of SFH.IV. 3 checked by TLC plates to obtain $\mathbf{1}(4.5 \mathrm{mg})$.

The ethyl acetate extract (30.1 g) was separated into five fractions, coded EA.I-EA.V, by silica gel column chromatography and eluted with hexane-ethyl acetate (1:1,1:3, v/v, respectively) and then chloroformmethanol (9:1, 4:1, 1:1, 0:1, v/v, respectively). Fraction EA.IV (5.3 g) was subjected to silica gel column chromatography and eluted with solvent systems of chloroform-methanol (1:0, 9:1, 4:1, 1:1) and further rechromatographed twice with the same procedure to give 2 (5.0 $\mathrm{mg}), \mathbf{5}(4.1 \mathrm{mg})$, and $\mathbf{6}(5.2 \mathrm{mg})$.

\section{RESULTS}

The chemical investigation on the S. foetida leaves collected in Binh Thuan Province led to the isolation of six compounds by the use of efficient separation techniques. From the hexane extract, three compounds $\mathbf{1}$, 3 , and 4 were isolated, while 2, 5, and $\mathbf{6}$ were isolated from ethyl acetate extract. Their ${ }^{13} \mathrm{C}-\mathrm{NMR}$ data were performed in Table 1 , and the following data were ${ }^{1} \mathrm{H}$ NMR data.

- Betulinic acid (1): HR-IDA-MS: $m / z 455.3512$ (calcd. for $\left[\mathrm{C}_{30} \mathrm{H}_{48} \mathrm{O}_{3}-\mathrm{H}\right]^{-}, 455.3525$ ). ${ }^{1} \mathrm{H}-$ NMR (chloroform- $d, \delta$ ppm, $J$ in Hertz): 3.19 $(1 \mathrm{H}, d d, 11.5,5.0, \mathrm{H}-3), 0.69(1 \mathrm{H}, d, 9.5, \mathrm{H}-$ 5), $0.97(3 \mathrm{H}, s, \mathrm{H}-23), 0.76(3 \mathrm{H}, s, \mathrm{H}-24), 0.83$ $(3 \mathrm{H}, s, \mathrm{H}-25), 0.93(3 \mathrm{H}, s, \mathrm{H}-26), 0.98(3 \mathrm{H}, s, \mathrm{H}-$ 27), 4.61 (1H, brs, H-29a), 4.74 (1H, brs, H-29b), $1.71(3 \mathrm{H}, s, \mathrm{H}-30) .{ }^{13} \mathrm{C}-\mathrm{NMR}$ (chloroform-d): see Table 1.

- Conyzasaponin G (2): HR-IDA-MS: $\mathrm{m} / z$ 781.4385 (calcd. for $\left[\mathrm{C}_{41} \mathrm{H}_{66} \mathrm{O}_{14}-\mathrm{H}\right]$, 781.4374). ${ }^{1} \mathrm{H}-\mathrm{NMR}$ (methanol- $d_{4}, \quad \delta$ ppm, $J$ in Hertz): $4.34(1 \mathrm{H}, b r s, \mathrm{H}-2), 3.64(1 \mathrm{H}$, d, 4.0, H-3), $5.28(1 \mathrm{H}, t, 3.0, \mathrm{H}-12), 2.88(1 \mathrm{H}$, $d d, 13.5,3.5, \mathrm{H}-18), 3.63(1 \mathrm{H}, d, 10.5, \mathrm{H}-23 \mathrm{a})$,
$3.27(1 \mathrm{H}, d, 10.5, \mathrm{H}-23 \mathrm{~b}), 0.97(3 \mathrm{H}, s, \mathrm{H}-24)$, $1.31(3 \mathrm{H}, s, \mathrm{H}-25), 0.86(3 \mathrm{H}, s, \mathrm{H}-26), 1.19(3 \mathrm{H}$, $s, \mathrm{H}-27), 0.93(3 \mathrm{H}, s, \mathrm{H}-29), 0.97$ (3H, $s, \mathrm{H}-30)$, $4.51\left(1 \mathrm{H}, d, 7.5, \mathrm{H}-1^{\prime}\right), 3.48(1 \mathrm{H}, d d, 9.0,7.5$, $\left.\mathrm{H}-2^{\prime}\right), 3.54\left(1 \mathrm{H}, m, \mathrm{H}-3^{\prime}\right), 3.46(1 \mathrm{H}, t$-like, 9.0, $\left.\mathrm{H}-4^{\prime}\right), 3.33$ (overlap, $\left.\mathrm{H}-5^{\prime}\right), 3.82(1 \mathrm{H}, d d, 11.5$, 2.0, H-6 $\left.{ }^{\prime} \mathrm{a}\right), 3.73$ (1H, dd, 11.5, 5.0, H-6 $\left.{ }^{\prime} \mathrm{b}\right), 4.52$ $\left(1 \mathrm{H}, d, 7.5\right.$. $\left.\mathrm{H}-1^{\prime \prime}\right), 3.32$ (overlap, $\left.\mathrm{H}-2^{\prime \prime}\right), 3.37$ $\left(1 \mathrm{H}, t\right.$-like, 9.0, $\left.\mathrm{H}-3^{\prime \prime}\right), 3.53\left(1 \mathrm{H}, m, \mathrm{H}-4^{\prime \prime}\right), 3.93$ $\left(1 \mathrm{H}, d d, 10.0,5.5, \mathrm{H}-5^{\prime \prime} \mathrm{a}\right), 3.30\left(1 \mathrm{H}, m, \mathrm{H}-5^{\prime \prime}\right.$ b). ${ }^{13} \mathrm{C}-\mathrm{NMR}$ (methanol- $d_{4}$ ): see Table 1.

- Taraxerol (3): APCI-MS: $m / z 409.36$ [M$\left.\mathrm{H}_{2} \mathrm{O}+\mathrm{H}\right]^{+} .{ }^{1} \mathrm{H}-\mathrm{NMR}$ (chloroform-d, $\delta$ ppm, $J$ in Hertz): $3.20(1 \mathrm{H}, b r d, 10.5, \mathrm{H}-3), 5.53$ $(1 \mathrm{H}, d d, 8.0,3.0, \mathrm{H}-15), 0.97$ (3H, $s, \mathrm{H}-23), 0.80$ $(3 \mathrm{H}, s, \mathrm{H}-24), 0.93(3 \mathrm{H}, s, \mathrm{H}-25), 0.82(3 \mathrm{H}, s$, $\mathrm{H}-26), 1.09$ (3H, $s, \mathrm{H}-27), 0.91(3 \mathrm{H}, s, \mathrm{H}-28)$, 0.95 (3H, s, H-29), 0.91 (3H, $s, \mathrm{H}-30) .{ }^{13} \mathrm{C}-\mathrm{NMR}$ (chloroform- $d$ ): see Table 1.

- Taraxer-14-ene- $1 \alpha, 3 \beta$-diol (4): APCI-MS: $m / z \quad 477.47 \quad\left[\mathrm{M}+2 \mathrm{H}_{2} \mathrm{O}-\mathrm{H}\right]^{-} . \quad{ }^{1} \mathrm{H}-\mathrm{NMR}$ (acetone $-d_{6}, \delta$ ppm, $J$ in Hertz): $3.56(1 \mathrm{H}, b r d$, 3.0, H-1), $3.68(1 \mathrm{H}, d d, 11.0,5.0, \mathrm{H}-3), 5.54$ $(1 \mathrm{H}, d d, 8.0,3.0, \mathrm{H}-15), 0.99$ (3H, $s, \mathrm{H}-23), 0.80$ $(3 \mathrm{H}, s, \mathrm{H}-24), 0.96(3 \mathrm{H}, s, \mathrm{H}-25), 1.14(3 \mathrm{H}, s$, $\mathrm{H}-26), 0.95(3 \mathrm{H}, s, \mathrm{H}-27), 0.85(3 \mathrm{H}, s, \mathrm{H}-28)$, 0.95 (3H, s, H-29), 0.93 (3H, $s, \mathrm{H}-30) .{ }^{13} \mathrm{C}-\mathrm{NMR}$ (acetone- $d_{6}$ ): see Table 1 .

- Fraxetin (5): ESI-MS: m/z 209.06 $\left[\mathrm{C}_{10} \mathrm{H}_{8} \mathrm{O}_{5}+\mathrm{H}\right]^{+} . \quad{ }^{1} \mathrm{H}-\mathrm{NMR}$ (acetone- $d_{6}$, $\delta$ ppm, $J$ in Hertz): $6.16(1 \mathrm{H}, d, 9.5, \mathrm{H}-3), 7.81$ $(1 \mathrm{H}, d, 9.5, \mathrm{H}-4), 6.77(1 \mathrm{H}, s, \mathrm{H}-5), 3.87(3 \mathrm{H}, s$, $\left.\mathrm{OCH}_{3}\right) .{ }^{13} \mathrm{C}-\mathrm{NMR}$ acetone- $d_{6}$ ): see Table 1 .

- Aesculin (6): HR-IDA-MS: $m / z 339.0720$ (calcd. for $\left.\left[\mathrm{C}_{15} \mathrm{H}_{16} \mathrm{O}_{9}-\mathrm{H}\right], 339.0716\right) .{ }^{1} \mathrm{H}-$ NMR (acetone- $d_{6}, \delta$ ppm, $J$ in Hertz): $6.19(1 \mathrm{H}$, $d, 9.5, \mathrm{H}-3), 7.81(1 \mathrm{H}, d, 9.5, \mathrm{H}-4), 7.47(1 \mathrm{H}$, $s, \mathrm{H}-5), 6.80(1 \mathrm{H}, s, \mathrm{H}-8), 4.84(1 \mathrm{H}, d, 7.5, \mathrm{H}-$ $\left.1^{\prime}\right), 3.51\left(1 \mathrm{H}, m, \mathrm{H}-2^{\prime}\right), 3.49\left(1 \mathrm{H}, m, \mathrm{H}-3^{\prime}\right), 3.46$ $\left(1 \mathrm{H}, t\right.$-like, 9.0, $\left.\mathrm{H}-4^{\prime}\right), 3.52\left(1 \mathrm{H}, m, \mathrm{H}-5^{\prime}\right), 3.91$ $\left(1 \mathrm{H}, b r d, 13.5, \mathrm{H}-6^{\prime} \mathrm{a}\right), 3.73(1 \mathrm{H}, b r d, 11.0, \mathrm{H}-$ $6^{\prime}$ b). ${ }^{13} \mathrm{C}-\mathrm{NMR}$ acetone- $d_{6}$ ): see Table 1 .

\section{DISCUSSION}

Compound 1 was obtained as a white amorphous powder. Its molecule was determined as $\mathrm{C}_{30} \mathrm{H}_{48} \mathrm{O}_{3}$ by the pseudo molecular ion peak at $\mathrm{m} / z$ at 455.3512 (calcd. for $\left[\mathrm{C}_{30} \mathrm{H}_{48} \mathrm{O}_{3}-\mathrm{H}\right]^{-}, 455.3525$ ). Its ${ }^{13} \mathrm{C}-\mathrm{NMR}$ spectrum showed 30 carbon signals of a triterpene skeleton whose most of the carbon signals resonated in the high magnetic zone from 14 to $56 \mathrm{ppm}$. An oxygenated methine signal at $\delta_{C} 79.0$ was assigned 

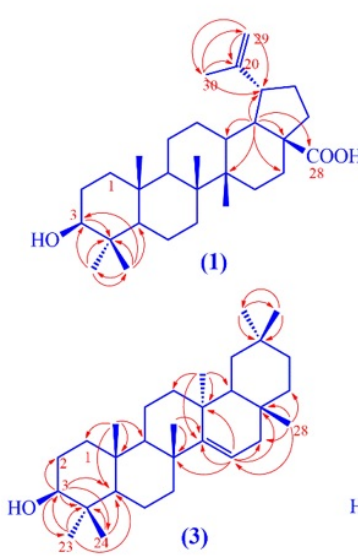

(3)

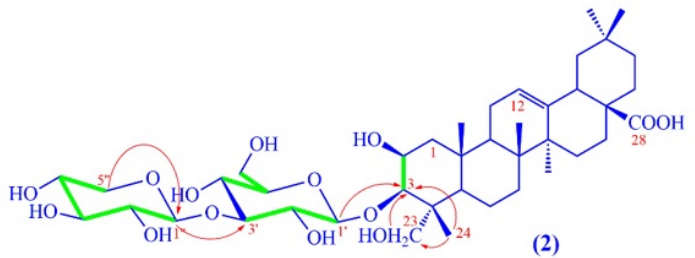

(2)

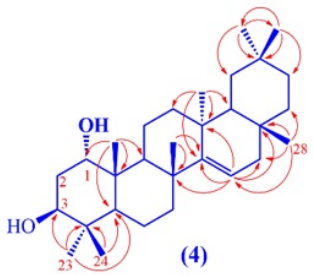

(4)

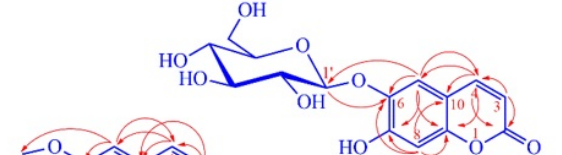

(6)

$\operatorname{HMBC}(\bigcirc)$ and $\operatorname{COSY}(-)$ correlations

Figure 1: The key HMBC and COSY correlations of compounds 1-6

to $\mathrm{C}-3$ as usual. Two signals at $\delta_{C} 150.4(>\mathrm{C}=)$ and $109.7\left(\mathrm{CH}_{2}=\right)$ were characteristic for C-20 and C-29 of a double bond in lupane skeleton. The lowest magnetic signal at $\delta_{C} 179.4$ belonged to a carboxyl group. These corresponded to the presence of two broadsinglet proton signals, each integrated 1 proton, at $\delta_{H} 4.61(\mathrm{H}-29 \mathrm{a})$, and $4.74(\mathrm{H}-29 \mathrm{~b})$ in ${ }^{1} \mathrm{H}-\mathrm{NMR}$ spectrum. These protons displayed HMBC cross-peaks to methine carbon $(46.9,>\mathrm{CH}-19)$, quarterany olefin carbon (150.4, C-20), and methyl carbon (19.4, $\mathrm{CH}_{3}$ 30). Therefore, the presence of isopropenyl group in lupane skeleton was proved. Five rest singlet methyl proton signals from 0.76 to $0.98 \mathrm{ppm}$ were assigned to $\mathrm{H}-23$ to $\mathrm{H}-27$. The axial-position of the oxygenated methine proton was confirmed by the signal at $\delta_{H}$ $3.19(1 \mathrm{H}, d d, 11.5,5.0)$, since the hydroxy group at $\mathrm{C}$ 3 was determined as equatorial- or $\beta$ - position. Based on the above analysis, $\mathbf{1}$ was elucidated as betulinic $\operatorname{acid}^{8}$.

The NMR analysis of $\mathbf{2}$ and $\mathbf{1}$ showed that $\mathbf{2}$ had one more hydroxyl group at C-2, one more hydroxymethylene instead of the methyl group, and two more sugar units. Two oxymethylene protons presented as two doublet signals at $\delta_{H} 3.63(1 \mathrm{H}, d, 10.5$, $\mathrm{H}-23 \mathrm{a}), 3.27(1 \mathrm{H}, d, 10.5, \mathrm{H}-23 \mathrm{~b})$ which had the same HSQC cross-peaks with carbon at $\delta_{C} 65.7$ and HMBC correlations with carbons C-3, C-4, C-24/C-23 since these two protons were $\mathrm{H}-23$ or $\mathrm{H}-24$. The chemical shift values of two methyl groups at C-23 and C-24 were around 28 and $15 \mathrm{ppm}$, respectively, as usual. In the case of 2 , one methyl was changed into oxymethylene group, and the rest methyl one was observed at
$14.7 \mathrm{ppm}$, which confirmed the position of the hydroxyl group at C-23. The presence of signals at $\delta_{H}$ $4.34(1 \mathrm{H}, b r s, \mathrm{H}-2)$ and $\delta_{C} 71.2(\mathrm{C}-2)$ of oxymethine group at $\mathrm{C}-2$ which was determined via COSY correlation between $\mathrm{H}-2$ and $\mathrm{H}-3$. The proton $\mathrm{H}-2$ in compound 2 appeared as a broad-singlet signal at $\delta_{H} 4.34$ which determined the equatorial-position of this proton or $\beta$-OH group at $\mathrm{C}-2$. The NMR spectra of 2 showed two anomeric proton signals at $\delta_{H} 4.51(1 \mathrm{H}$, $\left.d, 7.5, \mathrm{H}-1^{\prime}\right), 4.52\left(1 \mathrm{H}, d, 7.5 . \mathrm{H}-1^{\prime \prime}\right)$ and a serial carbinol signals from 3.2 to $3.9 \mathrm{ppm}$ as well as two anomeric carbons at $\delta_{C} 105.2$ and 106.0 and nine oxycarbon signals from 62 to $88 \mathrm{ppm}$ which determined the presence of one hexose and one pentose. The COSY spectrum revealed the connection of $\mathrm{H}-1^{\prime} / \mathrm{H}$ $2^{\prime} / \mathrm{H}-3^{\prime}, \mathrm{H}-4^{\prime} / \mathrm{H}-5^{\prime} / \mathrm{H}-6^{\prime}, \mathrm{H}-1^{\prime \prime} / \mathrm{H}-2^{\prime \prime} / \mathrm{H}-3^{\prime \prime} / \mathrm{H}-4^{\prime \prime} / \mathrm{H}-$ $5^{\prime \prime}$. The large coupling constant around 7.5 to $9.0 \mathrm{~Hz}$ of $\mathrm{H}-1^{\prime}, \mathrm{H}-2^{\prime}, \mathrm{H}-4^{\prime}, \mathrm{H}-1^{\prime \prime}, \mathrm{H}-4^{\prime \prime}$ assigned the axial position of all methine protons of $\beta$-glucopyranosyl and $\beta$-xylopyranosyl units. The positions of two glucopyranosyl and xylopyranosyl were determined at C-3 and C- $3^{\prime}$, respectively, by HMBC correlations of proton $\mathrm{H}-1^{\prime}$ with carbon $\mathrm{C}-3$, of proton $\mathrm{H}-1^{\prime \prime}$ with $\mathrm{C}$ $3^{\prime}$. The HR-IDA-MS of 2 showed pseudo molecular ion peak at $m / z 781.4385$ (calcd. for $\left[\mathrm{C}_{41} \mathrm{H}_{66} \mathrm{O}_{14}-\mathrm{H}\right.$ ], 781.4374). Based on the above analysis as well as the comparison NMR data of $\mathbf{2}$ with those reported in the literature $^{9}, \mathbf{2}$ was identified as conyzasaponin G.

The APCI-MS of 3 and 4 revealed the molecular ion peak at $\mathrm{m} / z 409.36\left[\mathrm{M}-\mathrm{H}_{2} \mathrm{O}+\mathrm{H}\right]^{+}$and $477.47[\mathrm{M}$ $\left.+2 \mathrm{H}_{2} \mathrm{O}-\mathrm{H}\right]^{-}$, respectively. NMR data of 3 and 4 displayed signals of triterpenes. The ${ }^{13} \mathrm{C}$-NMR showed 
a pair of signals at around 158 and 117 ppm of a double bond at C-14/C-15 in taraxerane skeleton, which corresponded to the presence of eight singlet proton signals of eight quaternary methyl groups in the range from 0.80 to $1.10 \mathrm{ppm}$. The ${ }^{13} \mathrm{C}-\mathrm{NMR}$ of 3 showed one oxymethine carbon at $\delta_{C} 79.0$ of C-3 as usual, while that of 4 revealed two oxymethine signals at $\delta_{C}$ 72.9 (C-3) and 71.8 (C-1). The HMBC spectra of 3 and 4 showed cross-peaks of proton $\mathrm{H}-23$ and $\mathrm{H}-24$ with carbon oxymethine C-3. Moreover, HMBC of 4 displayed a correlation of $\mathrm{H}-25$ with the rest oxymethine at $71.8 \mathrm{ppm}$. Therefore, the positions of two hydroxyl groups in $\mathbf{4}$ were determined. The proton $\mathrm{H}-3$ appearing as a signal with a large coupling constant of about $11.0 \mathrm{~Hz}$ assigned the $3-\beta-\mathrm{OH}$ whereas the small coupling constant with $3.0 \mathrm{~Hz}$ of $\mathrm{H}-1$ in compound 4 suggested the $1-\alpha-\mathrm{OH}$. The comparison NMR data of $\mathbf{3}$ and $\mathbf{4}$ with those reported in the literature, their structures were assigned as taraxerol ${ }^{10}$ and taraxer14-ene- $\alpha, 3 \beta$-diol ${ }^{11}$.

NMR spectra of compound $\mathbf{5}$ showed signals of a coumarin skeleton, including 9 carbon signals from 101 to $161 \mathrm{ppm}$, in which 3 methine carbons showed HSQC cross-peaks with three proton signals at $\delta_{H}$ $6.16(1 \mathrm{H}, d, 9.5, \mathrm{H}-3), 7.81(1 \mathrm{H}, d, 9.5, \mathrm{H}-4)$, and 6.77 $(1 \mathrm{H}, s, \mathrm{H}-5)$. The HMBC correlations of these protons (as shown in Figure 1) were used to determine their positions. At a higher magnetic field, the NMR spectra of 5 showed signals at $\delta_{H} 3.87\left(3 \mathrm{H}, s, \mathrm{OCH}_{3}\right)$ and $\delta_{C} 56.7\left(\mathrm{OCH}_{3}\right)$. This methoxy group was attached to $\mathrm{C}-6$, which was determined via HMBC cross-peaks between methoxy proton and carbon C-6. The ESIMS of 5 showed pseudo molecular ion peak at $\mathrm{m} / z$ $209.06\left[\mathrm{C}_{10} \mathrm{H}_{8} \mathrm{O}_{5}+\mathrm{H}\right]^{+}$. Compound 5 was identified as fraxetin via the good compatible NMR data of $\mathbf{5}$ with the reported data ${ }^{12}$.

The comparison NMR spectra of $\mathbf{5}$ and $\mathbf{6}$ showed that 6 was a coumarin glycoside. This was proved by the presence one more sugar unit and one less methoxy group. The proton NMR of $\mathbf{6}$ showed a set of signals including $\delta_{H}\left[4.84\left(1 \mathrm{H}, d, 7.5, \mathrm{H}_{-1}^{\prime}\right)\right.$ and 3.4-3.9 $(m)]$ and $\delta_{C}\left[104.7\left(\mathrm{C}-1^{\prime}\right)\right.$ and 62.5-78.2]. The constant coupling analysis of proton $\mathrm{H}_{-1}^{\prime}(d, 7.5)$ and $\mathrm{H}-$ $4^{\prime}$ ( $t$-like, 9.0) suggested that all methine protons of the sugar unit were axial positions. The HMBC correlation of the anomeric proton $\mathrm{H}-1^{\prime}$ and carbon $\mathrm{C}-6$ as well as all other HMBC correlations (as shown in Figure 1) confirmed the structure of $\mathbf{6}$. The HR-IDAMS of 6 showed a signal at $m / z 339.0720$ (calcd. for $\left.\left[\mathrm{C}_{15} \mathrm{H}_{16} \mathrm{O}_{9}-\mathrm{H}\right], 339.0716\right)$. Based on the above analysis, the structure of $\mathbf{6}$ was determined as aesculin ${ }^{13}$. CONCLUSION
In the continuous study on the leaves of Sterculia foetida Linn. collected in Binh Thuan province, four triterpenoids and two coumarin derivatives were isolated, including betulinic acid (1), taraxerol (3), and taraxer-14-ene- $\alpha, 3 \beta$-diol (4) isolated from the hexane extract and conyzasaponin G (2), fraxetin (5), and aesculin (6) isolated from the ethyl acetate extract. Their chemical structures were determined by the NMR, MS data analysis, and their spectroscopic data and physical properties with those reported in the literature.

\section{ABBREVIATIONS}

HR-IDA-MS: High resolution-Information dependent acquisition-Mass spectrometry

ESI/APCI-MS: Electrospray ionization/Atmospheric pressure chemical ionization-Mass spectrometry

${ }^{1}$ H NMR: Proton nuclear magnetic resonance

13 C NMR: Carbon-13 nuclear magnetic resonance COSY: Correlation spectroscopy

HSQC: Heteronuclear single quantum coherence

HMBC: Heteronuclear multiple bond correlation s: singlet

brs: broad singlet

$d$ : doublet

$\boldsymbol{d d}$ : doublet of doublets

m: multiplet

t-like: triplet-like

\section{COMPETING INTEREST}

The authors declare no competing financial interest.

\section{AUTHORS' CONTRIBUTION}

Pham N.K.T has contributed in conducting experiments, acquisition of data, and interpretation of data. Nguyen T. Q. T., Huynh C. D., Pham D. T., Nguyen T. D., Tran D. D. C., Huynh B. L. C., Nguyen T. A. T. interpreted NMR and MS data as well as searched the bibliography. Nguyen K. P. P. and Nguyen T. H. T gave final approval of the manuscript to be submitted.

\section{ACKNOWLEDGMENT}

Sai Gon University funded for this research under grant number CS2020-50. 


\begin{tabular}{|c|c|c|c|c|c|c|}
\hline No & $1^{c}$ & $2^{m}$ & $3^{c}$ & $4^{a}$ & $5^{a}$ & $6^{a}$ \\
\hline 1 & 38.8 & 44.4 & 37.7 & 71.8 & & \\
\hline 2 & 27.4 & 71.2 & 27.1 & 34.7 & 161.0 & 161.1 \\
\hline 3 & 79.0 & 84.0 & 79.0 & 72.9 & 113.3 & 113.6 \\
\hline 4 & 38.9 & 43.1 & 38.7 & 39.6 & 145.3 & 144.6 \\
\hline 5 & 55.4 & 49.5 & 55.5 & 48.7 & 101.2 & 117.8 \\
\hline 6 & 18.3 & 18.6 & 18.8 & 19.3 & 146.2 & 143.5 \\
\hline 7 & 34.4 & 33.9 & 41.3 & 41.9 & 140.2 & 153.0 \\
\hline 8 & 40.8 & 40.6 & 38.9 & 39.6 & 133.6 & 104.3 \\
\hline 9 & 50.6 & 48.2 & 49.3 & 41.1 & 139.7 & 152.7 \\
\hline 10 & 37.3 & 37.5 & 37.5 & 42.3 & 111.7 & 112.3 \\
\hline 11 & 20.9 & 24.7 & 17.5 & 17.2 & & \\
\hline 12 & 25.6 & 123.6 & 37.7 & 33.8 & & \\
\hline 13 & 38.4 & 145.4 & 35.7 & 38.4 & & \\
\hline 14 & 42.5 & 43.2 & 158.1 & 159.6 & & \\
\hline 15 & 30.6 & 28.8 & 116.8 & 117.2 & & \\
\hline 16 & 32.2 & 24.1 & 36.6 & 38.3 & & \\
\hline 17 & 56.3 & 47.3 & 38.0 & 36.5 & & \\
\hline 18 & 49.3 & 42.8 & 48.7 & 49.6 & & \\
\hline 19 & 46.9 & 47.3 & 35.1 & 37.3 & & \\
\hline 20 & 150.4 & 31.6 & 28.8 & 29.9 & & \\
\hline 21 & 29.7 & 35.0 & 33.7 & 33.8 & & \\
\hline 22 & 37.0 & 33.5 & 33.1 & 35.4 & & \\
\hline 23 & 28.0 & 65.7 & 28.0 & 28.5 & & \\
\hline 24 & 15.4 & 14.7 & 15.4 & 15.9 & & \\
\hline 25 & 16.1 & 17.5 & 15.4 & 16.8 & & \\
\hline 26 & 16.1 & 17.9 & 29.8 & 26.4 & & \\
\hline 27 & 14.7 & 26.5 & 25.9 & 21.6 & & \\
\hline 28 & 179.4 & 174.6 & 29.9 & 30.1 & & \\
\hline 29 & 109.7 & 33.6 & 33.3 & 33.5 & & \\
\hline 30 & 19.4 & 24.0 & 21.3 & 30.2 & & \\
\hline $1^{\prime}$ & & 105.2 & & & 56.7 & 104.7 \\
\hline $2^{\prime}$ & & 74.7 & & & & 74.6 \\
\hline $3^{\prime}$ & & 88.0 & & & & 78.2 \\
\hline $4^{\prime}$ & & 69.4 & & & & 71.3 \\
\hline $5^{\prime}$ & & 77.4 & & & & 77.5 \\
\hline $6^{\prime}$ & & 62.2 & & & & 62.5 \\
\hline $1^{\prime \prime}$ & & 106.0 & & & & \\
\hline $2^{\prime \prime}$ & & 75.3 & & & & \\
\hline $3^{\prime \prime}$ & & 77.7 & & & & \\
\hline $4^{\prime \prime}$ & & 71.0 & & & & \\
\hline $5^{\prime \prime}$ & & 67.1 & & & & \\
\hline
\end{tabular}

Note: c: chloroform- $d$, m: methanol- $d_{4}$, a: acetone- $d_{6}$ 


\section{REFERENCES}

1. Vo VC. Dictionary of medical plants in Vietnam. Medical Publishing House. 2002;p. 1083.

2. Xia PF, Feng ZM, Yang YN, Zhang PC. Two flavonoid glycosides and a phenylpropanoid glucose ester from the leaves of Sterculia foetida. Journal of Asian Natural Products Research. 2009;11(8):766-771. PMID: 20183322. Available from: https://doi.org/10.1080/10286020903055103.

3. Mujumdar AM, Naik DG, Waghole RJ, Kulkarni DK, Kumbhojkar MS. Pharmacological studies on Sterculia foetida leaves. Pharmaceutical Biology. 2000;38(1):13-17. Available from: https://doi.org/10.1076/1388-0209(200001)3811-BFT013.

4. Anjaneyulu ASR, Murty VS. Two rare tetramethyl ethers of quercetin from Sterculia foetida Linn. Indian Journal of Chemiscal Section B. 1981;20(1):87-88.

5. Kale SS, Darade V, Thakur HA. Analysis of fixed oil from Sterculia foetida Linn. International Journal of Pharmaceutical Sciences and Research. 2011;2(11):2908-2914.

6. Pham DT, Doan TDC, Nguyen TP, Mai DT, Pham NKT, Nguyen KPP. Quercetin derivatives from the ethyl acetate of the leaves of Sterculia foetida Linn. Vietnam Journal of Chemistry. 2018;56(4e):120-123.

7. Pham NKT, Nguyen TD, Doan TDC, Ha TD, Tran NMA, Tran TD, Mai DT, Nguyen TP. Stercufoetin A, new oleanane-type triterpenoid from the leaves of Sterculia foetida L. Natural Product Research. 2020;Available from: https://doi.org/10.1080/ 14786419.2019.1644508.
8. Satiraphan M, Pamornsilpadaharm P, Sittisombut C, Sotanaphun U, Raynaud F, Garbay C, Michel S, Cachet X. Lupane triterpenes from the leaves of the tropical rain forest tree Hopea odorata Roxb. and their cytotoxic activities. Biochemical Systematics and Ecology. 2012;44:407-412. Available from: https://doi.org/10.1016/j.bse.2012.05.014.

9. Su Y, Guo D, Guo H, Liu J, Zheng J, Koike K, Nikaido T. Four new triterpenoids from Conyza blinii. Journal of Natural Products. 2001;64(1):32-36. PMID: 11170662. Available from: https:// doi.org/10.1021/np000310v.

10. Xu R, Fazio GC, Matsuda SPT. On the origins of triterpenoid skeletal diversity. Phytochemistry. 2004;65:261-291. PMID: 14751299. Available from: https://doi.org/10.1016/j. phytochem.2003.11.014.

11. Li S, Shi Y, Shang XY, Cui BS, Yuan Y, Chen XG. Triterpenoids from the roots of Pterospermum heterophyllum Hance. Journal of Asian Natural Products Research. 2009;11(7):652-657. PMID: 20183302. Available from: https://doi.org/10.1080/ 10286020902964248.

12. Yasuda T, Fukui M, Nakazawa T, Hoshikawa A, Ohsawa K. Metabolic fate of fraxin administered orally to rats. Journal of Natural Products. 2006;69(5):755-757. PMID: 16724835. Available from: https://doi.org/10.1021/np0580412.

13. Yu M, Sun A, Zhang Y, Liu R. Purification of coumarin compounds from Cortex fraxinus by adsorption chromatography. Journal of Chromatographic Science. 2014;52:10331037. PMID: 24114664. Available from: https://doi.org/10. 1093/chromsci/bmt153. 